\title{
Logic of Integrity, Fuzzy Logic and Knowledge Modeling for Machine Education
}

\author{
Fatma Khanum Bunyatova \\ Intellect School, Baku, \\ Azerbaijan
}

\section{Introduction}

Fast development of ICT clearly shows how training is behind this development. Quick modification of process devices leaves far behind it hard on the modernization of education. Though new directions in teaching how to e- learning, m-learning, online learning, machine learning etc. were formed by ICT technical means, but these means are not yet in a position to influence the fundamental change in education. The reason is that educational principles existing more than 300 years of memory oriented traditional teaching didactics were invested into these technical means. Knowledge was memorized through the transfer of private, unsystematically, non-logically constructed knowledge. But as we know, besides human memory there is human cognition, whose reserves are used no more than 2-3\% (Gordon D., Jannette Voz 2000). Learning can be changed qualitatively and made accessible to all, if we make a shift from memorization and quantitative accumulation of knowledge to the organization of reasoning activities of students on knowledge for understanding. Learning in the mainstream of intellectual activity allows increasing the use of these resources several times and adequately raising the quality of education of all students. Cognitive activity - the activity of the intellect, is the area of psychology, the subject matter of its study.

Didactics - is the science about learning ways of a student, a science that seeks in more and more sophisticated ways to teach the students certain knowledge. Psychology of intelligence states that the knowledge that students receive is a reflection of what they have heard or read, in the best case, it is a converted form of information. The present knowledge should be built with the understanding of students on the basis of their previous experiences. New knowledge must be combined, divided, associated with previous and subsequent knowledge. Each student on the basis of his/her design of understanding constructs proposed knowledge in his/her understanding. In practice, it actually looks this way, but it is apparently only on the condition that a learner designs the structure of knowledge, structure of mental activity and structure of learning activities. Furthermore, these structures must be identical to the structures of intelligence. Under these conditions, a student regardless of learning forms, based on the capabilities of his/her internal understanding enters an active cognitive activity. Engaging in active learning activities, students gain active knowledge to expand their understanding. Knowledge, while at work, in such learning process destroys its traditional vertical structure of construction and it is 
logically arranged in a horizontal structure of thinking. That is, according to Piaget, Swiss psychologist "alogism of learning" is destroyed. Each new structure of knowledge, entering into logical operation with the old ones or adequate structures of the following knowledge builds them in the scheme of integrity of structures of knowledge. By taking advantage of high-tech, relying on psycho-pedagogy it is possible to model the contents of subject knowledge of isomorphic structures of intelligence. In this model, the following transfer and alignment occur:

\section{Conversion:}

a. The traditional concept of didactic unit of knowledge will be understood as the structure of knowledge;

b. Knowledge structures will be considered as the logical structures of knowledge of Bunyatova;

c. Traditional learning exercises will be completed by logical operations of thinking;

d. The logical structures of knowledge will be considered as the nanostructures of knowledge.

These conversions origin from the juncture of three sciences: pedagogy, psychology and high technology, which develop a new direction in the science of nanopsychopedagogy (F.Bunyatova 2009).

\section{Necessary fundamental changes in education}

To rotate learning from the position of memorization to the position of cognitive activity and for organization of learning without a student, it is needed to make the following fundamental changes in education:

a. Changing the way of learning

it is necessary to shift from the position of the transfer of knowledge to the position of the construction of the educational process, in which each student builds the knowledge based on his/her competence (Ф.Бунятова 2007). This means the transition from private practices to technology of training. In this case, the technology of constructive teaching by Bunyatova is applied (Ф.Бунятова 2009).

b. Modeling of structures of knowledge

The structures of subject knowledge should be modeled. This model should be constructed similar to models of natural and artificial intelligence brain (Лотфи Заде 1976).

c. Model of natural intelligence

The model of natural intelligence was constructed by Piaget and of artificial intelligence was constructed by Zadeh. Logic integrity of J. Piaget or the work of reasoning at an operational level that is at the formal-logical level is the work of human brain (Р.Алиев 1999) .

d. Model of artificial Intelligence by Zadeh

Zadeh had created an SC, which provided joint use of such numerical new approaches as fuzzy logic, neural networks, evolutionary computing, etc. These technologies are important for data compression and system design with high MIG and the best model of SC is human brain as noted by Zadeh (Р.Алиев 1999). 
e. Building of holistic logic and fuzzy logic models of knowledge on the basis of these two theories

On the basis of these two theories, holistic logic and fuzzy logic models of knowledge are built F.Bunyatova (2009). This model can be a psychopedagogical and technologically constructed model for subject knowledge of not only machine learning in all its directions, but for learning in a whole. This model is constructed from the perspective of pedagogy, psychology, and high technology.

These three principles as a result, change not only the form and method of learning, but also the structure of contents of learning. Students here do not gain knowledge. They, relying on their experience construct them by means of logically constructed structures of knowledge. These structures of knowledge are built by isomorphic structures of intelligence.

\section{Creative learning technology by Bunyatova - CT by Bunyatova}

Change of the way of training means shift from private practices to the technology of training. In this case, technology of constructive teaching by Bunyatova is proposed. This technology is based on the cognitive theory by Piaget. Constructive teaching technology aims to develop structures of intelligence of students and organize their reasoning activities over knowledge.

Constructive teaching is a creative, activity-and operational learning, which provides an opportunity for each student to build new knowledge, based on his/her experience and available knowledge. The philosophy of constructive teaching is a synthesis of Eastern and Western philosophy of learning; this is a shift from private knowledge to the integrity of knowledge or the vice versa from the integrity of knowledge to the private. The constructive teaching is aimed to change the form of activities of learning and a student in the learning process, which in the end leads not only to the change of learning process, but all its relevant components.

CT by Bunyatova takes its origins from the psychology schools of Piaget and Vigotsky; it contains the co-operative structure of the educational activities of the American psychologist Spencer Kagan. While establishment of machine learning classes, the CT principles do not change principally, they just bear an individual character of learning, enriching the methods of individual learning.

\section{Principles of constructive teaching by Bunyatova}

\section{Principle 1. Searching meaning of the topic}

The lesson in a constructive teaching starts with searching the theme of the lesson, that is determines the real understanding of entity of the study. The teacher poses questions for discussion. Answers of students generate new questions and new discussions. Students, by discussing, actively adapt their knowledge and attitudes to these logically designed questions. In this process, they may make mistakes, go the wrong way, go back and start again. By scientific definition of meaning, they come from the definition of that meaning with their personal terms. In the interaction of ideas, in online education, these personal definitions, by self-correcting, self-regulating and self-enriching transform into a new structure of knowledge. 


\section{Principle 2. Integrity scheme of knowledge structure}

Structures of knowledge in constructive teaching are provided for studying in the scheme of integrity. Knowledge is divided into invariant and variable (example: in language studies invariants - are parts of speech, in mathematics - they are figures; variables - are the rules of language, and in math they are mathematical operations and etc.). For example, if we study the numeral, then the scheme of integrity will be constructed as follows: the numeral in the middle, to the left of previous knowledge - adjective, noun, and to the right following pronoun, verb and adverb. In the end, it will be as follows: a noun, adjective, numeral, pronoun, verb and adverb. At the end, the scheme will be the following: noun, adjective, numeral, pronoun, verb and adverb. In this scheme of integrity, the numeral is studied in depth in a combination of relations, connections and interdependence with a noun, adjective, pronoun and verb in the system of integrity of the language.

\section{Principle 3. Logical structures of knowledge by Bunyatova - LSK by Bunyatova}

Using the tools of integrity logic by J. Piaget in the contents of subject studies have been identified following logical connections, relationships and dependencies among the structures of knowledge (Ф.Бунятова.2001)

- $\quad$ Agreed structures

Two structures of knowledge, agreeing with common relationships are connected and form a new structure of knowledge.

- $\quad$ Reversible structures

United by common relationships, structures of knowledge are reversible and transformed.

- $\quad$ Associated structures

Thinking always retains the ability to rejection and finding other variants of solution. The result obtained in various ways, in all cases is the same.

- $\quad$ Annulled structures

The structure of knowledge is annulled, disappears, canceled if it is multiplied by zero.

- Identical structures

Two identical structures can be combined into one complex structure.

The logical structure of knowledge (LSk) identified in knowledge, are the load bearing parts of constructive teaching.

\section{Principle 4. Logical operations of thinking}

In the analysis of tasks to the subject in the traditional way of learning it is revealed that most of the tasks are included in the exercises, that is repeating same actions in order to assimilate it, which consist of finding, underlining, determination, etc. These tasks are performed on one or two of the structures of knowledge and are aimed to determine the level of knowledge and skills. 
In constructive teaching besides this on the structures of knowledge are performed logical operations of thinking. These operations allow students to integrate structures of knowledge into groups to clarify their interrelationship and relationship, classify, enrich, or replace them with other structures. A student, performing thinking activities of such operations on the structures of knowledge adequately builds the structure of his/her thinking and logical structure of his/her knowledge. Logical operations on the structures of knowledge are performed by commands or setting of a student.

1. The operation of classification

With the assistance of this operation, students acquire intellectual skills of the partition of the set into subsets according to certain criteria.

2. The operation of seriation

Performing the logical operation of seriation on structures of knowledge, students form intellectual skills of grouping structures of knowledge according to their combining criteria or for only one criterion.

\section{The operation of substitution}

By this operation structures are replaced by others (for example, in mathematics, numbers replaced by letters $(6+7)=(a+b)$; replacement of signs $5 \times 5=5^{2}$, etc.). This is very basic logical operation on the structures of knowledge and intellectually important skill that qualitatively transforms knowledge. This operation destroys the vertical structure of knowledge and develops in students the ability to arrange them into thinking in a horizontal structure [6].

4. The operation of enrichment

In carrying out this operation on the structures of knowledge, students who have knowledge enriched their knowledge with new structures of knowledge and turn it into new knowledge. The operation of enrichment, as the operation of substitution, generates future knowledge from the acquired knowledge.

\section{Multiplicative operations}

This operation is used simultaneously on multiple structures of knowledge that have common relations or communications (example: in a linguistic knowledge it is the change of some parts of speech - on cases, by the numbers.

\section{Principle 5. Mental models of students}

According to psychology of intelligence by Piaget, a child from birth to 8 years old goes through a pre logical operations; from 8 to 12 years, the stage of concrete operations, and from 12 to the end of youth stage of formal operations. Each stage of development corresponds to its settings, its commands. Under pre logical operations stage students typically argue based on their life experiences, and try as much as possible to extend it with such tasks that are set for them. In the bowels of pre logical operations students in a logical setting ask teacher questions generated by the makings of concrete operations, which are expanded, enriched, balanced and smoothly go to transition to the stage of concrete operations. In the frequent repetition of the same commands, units of the structures of 
knowledge, students gain not only stable knowledge, but also reveal their relationship and communication with other structures of knowledge. The concretization of knowledge and its consideration in relations and connections, allow the student to generate knowledge based on previous knowledge, or by identifying stable relationship, connections among the structures of knowledge, he/she formalizes them and moves to the stage of formal operations. It can be said that knowledge of every student in a constructive teaching goes through three stages: intuitive, concrete and formal. Quantity of previous knowledge through these stages is the result of intelligence, its richness, its diversity.

\section{Principle 6. Lesson structure}

The lesson in constructive teaching is designed structurally. The learner designs logical structures of knowledge, structures of mental activity and structure of the learning activities of students.

\section{The structure of mental activity}

Construction of thinking and cooperative structure activities are designed in isomorphic stages of intellectual development of students. Over the logical structures of knowledge students perform mental operations. This intellectual activity of students individually or in co-operation builds, destroys, strengthens and develops structures of intelligence of each separately helps a student to build his/her own individual way of thinking, understanding, which he/she later turns into personal tool of knowledge.

\section{Structure of educational activities}

Learning activities of students can be individual or interactive. For organization of an interactive activity students use cooperative learning structures of American scientist Spencer Kagan. Interaction of students in these structures leads to reflection, which is one of the major factors in construction of knowledge. Social skills acquired in the structures of interactive activities are combined with the intellectual skills that are generated by thinking activity.

Each lesson in constructive teaching is designed by the teacher in advance. For design of the lesson of constructive teaching 7 elements are used.

\section{Seven elements of constructive teaching}

While establishing a lesson, the CT uses the following elements:

\subsection{Search}

The teacher poses questions to the subject, to determine what students know about the topic what they will do, what decisions will be taken and what conclusions they will come. Search is to identify the essence of the meaning of the theme, determine its place in the system of knowledge; search - it is a motivation of cognitive activities of a student and understanding of given tasks from his/her pyramids of knowledge. Search - it is a concept for a teacher, how well students understand and explain the topic. Search - it is definition by the teacher zone of knowledge of students about the given subject and the prospect of its extension and application. Search - are statements by teachers to bring students on the track, which he has drawn. 


\subsection{Structures}

In constructive teaching, as mentioned above, the lesson is built structurally:

1. It is a structure of knowledge. Based on the content of the topic, the teacher finds the goal in subject knowledge of logical structure of knowledge, that is, he/she can logically combine and separate one structure of knowledge from other structures; each structure of knowledge beyond that may be associated, coincide with another, or generally, after the actions on it, eliminated.

2. Having identified the logical structures, the student determines for himself/herself what mental operations students will perform over the logical structures of knowledge.

3. It is a structure of educational activity. A teacher, making the design of the lesson, determines which determines in which structures of activity students will work in pairs or in teams.

\subsection{Logical operations of thinking}

In a traditional approach to education work on exercises, examples, tasks are usually expressed as assignments: underline, find, agree, put in the required form, solve, run, etc. All these tasks are aimed at numerous varying repeat of learned and its application to one or two structures of knowledge. In contrast to this approach in constructive teaching several logically built mental activities, that is, operations are performed over the knowledge. Mental operations, or operations of thinking - they are commands, setups, expressed in verb, for example, isolate and connect the appropriate, replace one another, and convert and explain the outcome, express in a different form and create a new, etc. Students by regularly performing tasks over these settings, then in the follow up these settings gradually turn to their instrument of knowledge.

\subsection{Connection}

This element serves for connecting a structure of knowledge with others. In constructive teaching, knowledge is represented in the scheme of integrity. In this scheme of integrity it is clearly visible not only structural connection inside of the subject of knowledge, but also interdisciplinary communications. This communication allows for considering the subject matter under scrutiny from different viewpoints, identify among them the similarities and differences, determine its compatibility, identify options and make replacement of certain knowledge with others.

\subsection{Questions}

In a constructive teaching, the learner by making lesson design should determine with what question he will start the lesson and with what question he will finalize it. The questions posed by training, help him determine what students know about the topic, how they imagine it, how they by arguing explain their vision. Responses of students may be correct and not correct, complete, or short, and the whole spectrum of responses of students which were received by the training gives him an opportunity with the help of same training go to the right answer, that is to the point of knowledge to which he moved purposefully. 


\subsection{Adjunction and connections}

This element of the lesson serves as communication of knowledge under study with past and future knowledge. Addition of a student in this communication of knowledge often changes them qualitatively and that knowledge of high school by moving down becomes knowledge of junior classes. This means the integration of knowledge horizontally, that is, integrity of knowledge is built, which creates a large space for the flight of thought.

\subsection{Reflection or rejection (Presentation or a reflection of the students accumulated)}

Presentation is the last element in the design of the lesson of constructive teaching. Teacher, in constructive teaching, prepares worksheets in advance for both individually and gives tasks on the basis of its set goal. Tasks and settings should cover work done in classes; they must start from easy and smoothly move to a more complex, which includes not only understanding, but also a deep comprehension and the transition of this meaning to a higher level, to the level of generation of new knowledge.

\section{Modeling knowledge structure}

In a traditional training, the structures of knowledge are established vertically and students get a comprehensive knowledge through the educational years. In the example of Russian, we can say that, at the primary school, students do not get holistic knowledge of a language. A student accomplishes this holistic knowledge in only $6^{\text {th }}$ year of education. Such a set of knowledge leads to fragmentary and non-systematic knowledge. This knowledge as a whole can only be kept by memorizing. Therefore, it becomes difficult to students to find ties, relations, adequacy, and etc between knowledge. Logic modeling of the structures of knowledge allows building a structure of subjective knowledge in the scheme of integrity. Study of the structures in this scheme allows the students to build his knowledge adequately and hold them in a manner of the logic operation of thinking.

\section{Building a formal logic model of a language on the basis of the logic of integrity by Piaget}

The model of natural intelligence was established by Piaget. The logic integrity of J. Piaget or the work of sense, at an operational level, that is the level of formal logic, is the work of human brain.

Piaget developed this model in a natural language. Hence, we can say that if the cognitive logic is established in a natural language, then this natural language itself can be adequately and logically structured. Building of a fuzzy-logic language model will be constructed on the basis of Russian by the logic of integrity.

1. By terms of "groups" and "grouping", Piaget define a certain equilibrium form of intellectual operations, that is, actions interiorized and organized in the structure of integrity (Ж.Пиаже 2001).

The structure of integrity of Russian comprises of 10 parts of speech.

Note: In Russian, 6 of the parts of speech are independent and 4 of them are supportive. Independent parts of speech are the noun, the adjective, the numeral, the pronoun, the verb 
and the adverb, and the support parts of speech are the proposition, the conjunction, the interjection and the determiners.

The act of intelligence organized in the holistic structure is transferred by holistic structures of Russian. In this case, these actions are transferred by the holistic structure of Russian.

2. Piaget established 4 stipulations for the "groups" of mathematical order and 5 stipulations for "groupings" of quality orders.

According to a psychological theory of Piaget, "groups" and "groupings" definitions compare the following definitions of the Grammar of Russian:

"Groups" and "groupings" fall in the framework of integrity. Within the framework of integrity, there are 10 parts of speech in the language. Piaget consecutively compares the psychological definition of "groups" with the parts of speech in Russian (at the same time, in any language).

Hence, the operational "groups" of the natural language will be 10. Encoding these groups or the parts of speech, that is, altering the logical operation, we get the following holistic structure of the language:

1 -Noun; 2 - Adjective; 3 - Numeral; 4 - Pronoun; 5 - Verb; 6 - Adverb; 7 - Proposition; 8 - Conjunction; 9 - Interjection; and 10 - Determiner

1 ----2----3----4----5----6----7----8-----9----10

We will consider "the groupings" in this holistic structure of the language as word groups bearing common features. For example: 2 ----3 ----4----5---, 6 - are grouped as words approached to an object;

Groupings 7----8----9----10 are supportive words, which are not used independently. At the same time, in these "groupings", the parts of speech can be combined with each other in terms of relations and features, that is, within the framework of the holistic system in a new arrangement, related to quality.

For example: 1 ----2; 3 ----4; 1 ----5; 5 ----6; 3 ----4; 4 ----5, etc.

Note: 1 ----2; 3 ----4; 4 ----5 coincide with each other in terms of gender, quantity and the cases of noun).

3. The way of "grouping"

How are these psychological rules of Piaget interpreted and compared with the language rules?

- Two of the elements of "Grouping" may coincide with each other and as a result, may form a new element or a new unit of knowledge.

From the point of a language, it is understood like this:

For example: new - 2; home - 1. Combination of 1 - noun (home) and 2 - adjective (new) forms a new element of knowledge - phrase of new home;

Two relations $\mathrm{A}>\mathrm{B}>\mathrm{C}$ may be $\mathrm{A}>\mathrm{C}$, where they exist. 
For example, 1 - egg 5 - broils 6 - light: can also be expressed like this: 1 - light 6 - egg light egg.

Note: Although the verb defines the action of an object and the adjective defines the character of the action, the adverb defines the character of the noun.

- All forms of transformation are available. For example, new home; if we separate these phrases, we can get the followings: 2 - new; 1 - home;

- The composition of the operations is "associated". A physical definition of composition is commented as consideration of the roles of "groupings", that is, the parts of speech from the points of morphology and syntax.

For example: A strong wind started to blow in the morning. In this sentence, from the point of point morphology, strong - is a supportive pat of the speech and wind is a key part. From the point of syntax, the phrase of strong wind is a sequence, that is? These words coincide in terms of gender, quantity and case of noun.

- An operation united with its repeated operation, it is cancelled, for example:

Home (noun in singular) + home (noun in singular) = homes (noun in plural) repeated operation - homes $=$ home (noun in singular).

- Identical operation - In the knowledge of language, it reconciles the combination of two simple sentences or words in a complex sentence or phrase.

For example: The sky suddenly got darkened. It started raining strongly. Suddenly the sky got darkened and it started raining strongly ...

\section{Forming of groupings or the parts of speech}

The system of "groupings" is formed through, so-called, logical operations. The logical operations of thinking are understood in the context of language meanings as logical units for conversion or consecutive exercises.

Such operations are implemented as follows:

- A present cluster of words are classified and are subjected to seriation:

книга, стол, дом, земля, девочка, тетрадъ, ученик,юноча, знамя, соня, лочадь, поле, окно, время, солнце. денъ, конь.

book, table, house, girl, copybook, school-child, youth, flag, dormouse, horse, field, window, time, sun, day, foal.

1. the first operation is the operation of classification, that is, classification of words in terms of gender.

Note: In Russian, the nouns are divided into three genders or three categories in terms of their endings:

The feminine gender includes the words with endings of $\mathbf{- a}, \mathbf{- я ,}, \mathbf{- \mathbf { g }}$ and $\mathbf{- \mathbf { b }}$. The masculine gender includes the words with no ending, with ending of $\mathbf{b}$, and in some words, with endings of $\mathbf{- a}$ and $\mathbf{- \boldsymbol { r }}$. The neuter gender includes the nouns with endings of $\mathbf{- o}-\mathbf{e}, \mathbf{-} \mathbf{- b}$, and in 10 words, with -мя. 
Class 1: the words of feminine gender:

книга, земля, девочка, соня

book, land, girl, dormouse

Class 2: the words of masculine gender:

стол, ученик, юноша

table, student, youth

Class 3: the words of neuter gender:

знамя, поле, окно, время, солнце

flag, field, window, time, sun

Class 4: the words having two ways

конь, лошадь, мышь

foal, horse, mouse

Note: Identification of the gender of the words subject to Class 4 is performed through transformation, that is, by changing of these words in terms of cases of the noun.

нет коня (masculine gender) нет лошади - feminine gender

There is no foal. There is no horse.

Class 5: It includes the words with ending of - мя; these words are declined as nouns of neuter gender

At the present case, the operation of classification coincides with division of nouns into gender.

2. The second "grouping" is formed though the operation of seriation of appropriate endings. The operation of seriation coincides with declination.

Note: There are three forms of declination in the grammar of Russian:

Form 1 includes the words with endings of -a , -я and ья;

Form 2 includes the words with no endings and endings of $-\mathbf{b}$;

Form 3 includes the words with endings of -o, -e and -ье.

Serial 1:

words with endings of $-a,-я$ (книга (book) -feminine; земля (land) -feminine, девочка (girl) -feminine, юноша (youth) - masculine, соня (dormouse) - feminine and masculine)

The words of this serial includes the nouns of feminine gender and some words of masculine gender, with endings of $-\mathrm{a}$ and -9

Serial 2:

The words with no endings of the masculine gender and the words of the neuter gender with endings of $-\mathrm{o},-\mathrm{e}$, and -ье.

стол,ученик, поле, окно, солнце.

table, student, field, window, sun 
These words are transformed, that is, declined in a same manner

\section{Serial 3:}

This serial includes the words of the feminine gender with ending of -ь (лошадь - horse, мышь - mouse, дочь - daughter)

Serial 4:

Words with ending of -мя. There are only 10 words with such an ending in this language and they are exceptions.

The operation of seriation in Russian is subject to declination of nouns. So, Serial 1 is subject to the first declination; Serial 2 to the second declination; and Serial 3 to the second declination. Serial 4 is an exception.

The operations of classification and seriation form "groups" and "groupings". And with the remaining operations are used to form "sub-groups" and "sub-groupings".

3. The third major operation is the operation of alteration. It replaces a definition or a word with another one. In the Russian grammar, it is equal to definitions of synonyms, antonyms and homonyms.

4. The fourth operation is the operation of enrichment. It has relationship uniting elements of one or another class, that is, equivalence.

For example: 1 -школа (school), 2-новая (new); 1-- school), 3- одна (alone); 1-школа (school), 4 моя (my) 1 -школа (school); 1- школа (school) 5-строится (to be built); 5строится (to be built) 6--- быстро (rapidly).

5. Multiple operations are those that are included to more than one system at a given period.

Note: For example: A category of declination, the number covers 1 --- 2 --- 3 ---4; and the category of number covers 1---2---3-4---5.

As said above, the structures of knowledge are divided into invariant and variable ones.

Invariant structures of knowledge are the parts of speech or the "groups".

Variable structures are categorical structures of knowledge.

Note: There are 10 categories of language in Russian.

While modeling subject knowledge, the invariant structures are placed in horizontals of coordinate planes, but the variable ones are placed vertically. In this coordinate plate, the parts of speech of $1,2, \ldots . .9,10$ will be placed horizontally and1.2,3,......10 language categories will be placed vertically.

While the study process, the structures of the knowledge of formal logic model of a language are subjected to logical operations of thinking.

Exactly these two important points - logical construction of knowledge and logical operations transform these separate structures of knowledge into a logical model, which is adequate to the way of building of thinking. 


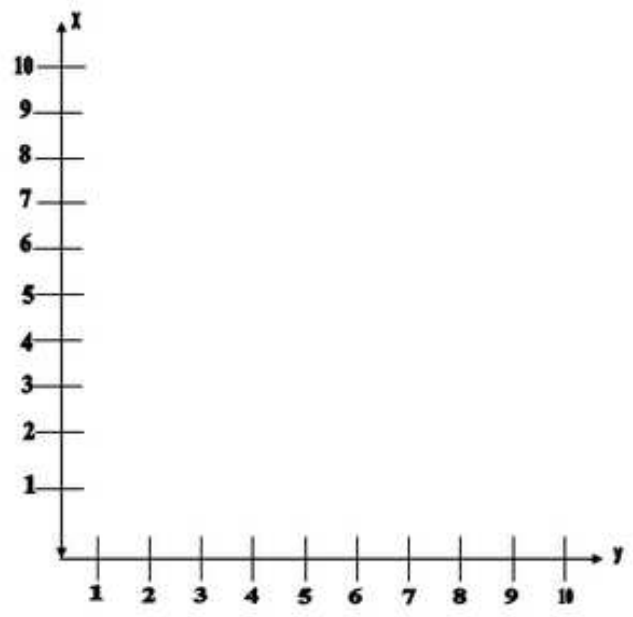

Sxem $\mathrm{Nil}$

\section{Definition of Zadeh's fuzzy logic theory}

Mathematical theory of fuzzy sets by Zadeh has allowed since more than a quarter of a century ago up to now to describe fuzzy definitions and knowledge and operate with this knowledge as well as make fuzzy outputs. (Пивкин , Бакулин и др)

The universal set is indicated by - E

Elements of a set are indicated by -- $X$

$\mathbf{R}$ - Indicates several properties, and $x$ - indicates element $\mathbf{E}$.

Ordinary (certain) Sub-set A of Universal Set E, whose elements

content the Property $\mathrm{R}$, is indicated as the set of Ordered Pairs $A=\left\{m_{A}(x) / x\right\}$, where $m_{A}(x)-$ is a characteristic function, accepting

Value 1, if $x$ contents Property $\mathbf{R}$, and vice versa $\mathbf{0}$.

Difference of a fuzzy sub-set from a certain one is that there is not a single valued answer "yes-no" for the elements of $x$ of E, regarding Property $\mathbf{R}$.

In this respect, Fuzzy set A of Universal set $\mathbf{E}$ is indicated as the set of Ordered Pairs $\mathbf{A}=$ $\left\{\mathbf{m}_{\mathrm{A}}(x\right.$ of Sub-set $\mathbf{A}$ of Universal Set $\mathbf{E}$.

\section{Comparison of psychological theories by Piaget with mathematical theories of Zadeh}

Let us understand the term "a universal set" by Zadeh as "groups" and "groupings" or the vocabulary of a language and sign it though - E. Then, the "elements of a set" by Zadeh and "groups" by Piaget will be considered as the parts of speech. Let us sign these elements by $x$. 
As we mentioned above, there are 10 parts of speech in Russian. Let us sign each part of speech by $-x$. Then $x 1$ will be a noun, $x 2-a$ adjective, $x 3-$ a numeral, $x 4-a$ pronoun, $x 5-a$ verb, $x 6$ - an adverb, $x 7$ - conjunction, $x 8$ - proposition, $x 9$ - determiner, and $x 10$ interjection. Hence, Universal Set $\mathrm{E}$ has 10 elements $x 1, x 2, \ldots \times 10$. If we note the element of Universal Set E by 0, 1, as marks of a set, then 0,1 - the word indicates an object; 0,2 - a property of the object; 0,3 - the quantity of the object; and 0,4 points out the object; 0,5 indicates action of the object; and 0,6 indicates a sign of the action. 0,7 is a conjunction; 0,8 is a proposition; 0,9 is a determiner; and 1 is an interjection.

The parts of speech of Russian, according to the psychological concepts by Piaget, are "groups", and according to mathematical concepts by Zadeh are "elements of a set".

Parts of speech - "groups" - "elements of a set"

$X$ - an element of Set $E$

Let us sign the properties of this element by $-R$

Note. Each part of speech has its own properties - internal rules, which have relationship with rules of other particles of the speech, that is, elements of a set.

The "fuzzy set" may be presented in a form of a language vocabulary.

Then, under functions of properties of the "fuzzy set", the words will be interpreted in a direct lexical meaning. For example: дом (house), стол (table), берег (coast), океан (ocean), and etc.

Proceeding from concepts of linguistic variable by Zadeh, the membership function corresponds to two rules:

1. syntactical, which is set in the form of a grammar that generates the title variable in the form of language categories.

2. semantic, which determines the procedure to compute the meaning of algorithmic each value.

Then, $Y$ - will indicate the grammatical rules of the language, and $X$ - the parts of speech, which also have their own rules.

Rule $X$ will comply with Rule $Y$, as Rule $Y$ complies with Rule $X$.

Then, in this property function:

$x 1-$ is a noun;

$x 2-$ is an adjective;

$x 3$ - is a numeral;

$x 4$ - is a pronoun;

$x 5$-is a verb;

$x 6$ - is an adverb;

$x 7$ - is a conjunction;

$\mathrm{x} 8$ - is a proposition;

$\mathrm{x} 9$ - is a determiner; and

$\mathrm{x} 10$ - is an interjection.

$\mathrm{y}$ - are categories of a language: -

$\mathrm{y} 1$ - is the category of quantity - singular and plural 
y2 - are the categories of gender - feminine gender (1), masculine gender (2), and neuter gender (3);

y3 - is the category of case (1-6) ;

y4 -are the categories of person;

y5 - is the category of person;

y6 - is the category of tense;

y7 - is the category of type;

$\mathrm{y} 8$ - is the category of declination;

y9

$\mathrm{y} 10$

\section{Replacing the formal logic model of the language with the concepts of linguistic logic by Zadeh the model of formal-fuzzy logic at the example of Russian lanqiaqe}

Replacing the concepts of formal logic by Piaget with the linguistic logic by Zadeh, we get the following fuzzy model of the language: (F.Bunyatova 2009]

(a) If we replace the definition of "groups" with the definition of "elements of a set", then under "set" we will consider "groups" and" groupings" within the framework of holistic.

$X 1, x 2, ; x 3 \ldots x 10$ will be elements of Set $\mathrm{E}$

Under the "groups" will turn the whole vocabulary of the language, and Universal Set $E$ - will consist of the vocabulary of Russian.

The variable and invariant concepts will be replaced with the concepts of linguistic variable.

The variable concepts - are grammatical categories of the language and they will be indicated by $Y$.

We can indicate the invariant concepts with $X$.

The Scheme of Fuzzy Model of Language

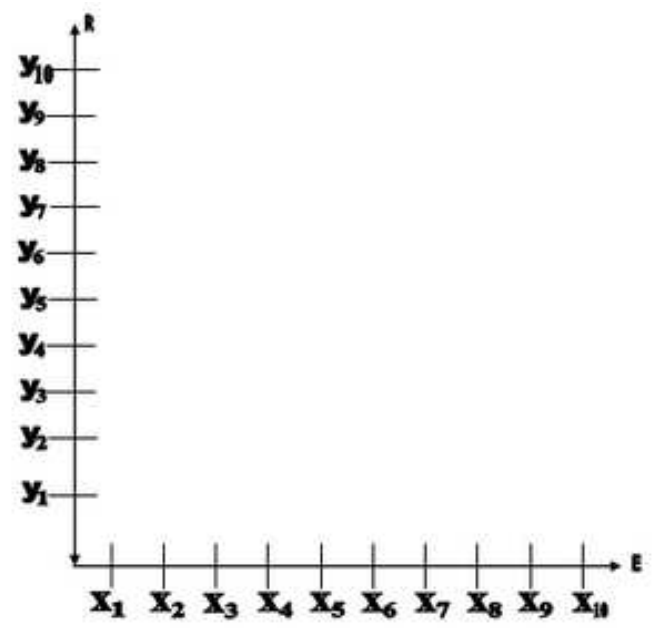

Sxem Ne? 
This fuzzy model of a natural language, treating the conversion of the definition tool of the logic by Zadeh, gets the following form:

1. Fuzzy set may have an end or may be endless; as a part of speech it has an end, but as a vocabulary of a language it is endless. $X=(x 1, x 2 \ldots-x 10)$

2. Fuzzy set A may be characterized by a set of pairs (composition according to the logic by Piaget): $A=E x$

For example: $x 3$ - $x 1$--один мальчик (one boy) , $x 2-x 1$-- высокий мальчик (a tall boy) ; x1x4 мой друг (my firend), etc.

3. Fuzzy set A may be presented in the following form:

(We present the noun in the form of $\mathrm{A}=0,1$ - игра (gате): 0,1 $\square+0,2$-сильная игра (a strong game); 0,1+ +0,3;-

одна игра (a game); 0,1+ 0,4;-моя игра (my game); etc.

4. The operation of unification

Unification of two fuzzy sets $A$ and $B$ will be specified as the following: if $A-1$-is a noun, and $B-2$ is an adjective, then the function of property $\mathrm{y} 1$ and $\mathrm{y} 2$ belongs to $A$ and $B$.

Based on the abovementioned conversion, the sentence: "На улице стоял сильныи мороз" (There was heavy snow on the street) will be indicated as signs like the followings:

$$
x 7-x 1 y 2 y 3 / 6-x 5 y 2 y 5-x 2 y 1 y 2 y 3-x 1 y 1 y 2 y 3
$$

If we present this sentence in a coordinate plane, this sentence graphically may be indicated as spots in that coordinate plane:

$$
x 7-x 1 y 2 y 3 / 6-x 5 y 2 y 5-x 2 y 1 y 2 y 3-x 1 y 1 y 2 y 3
$$

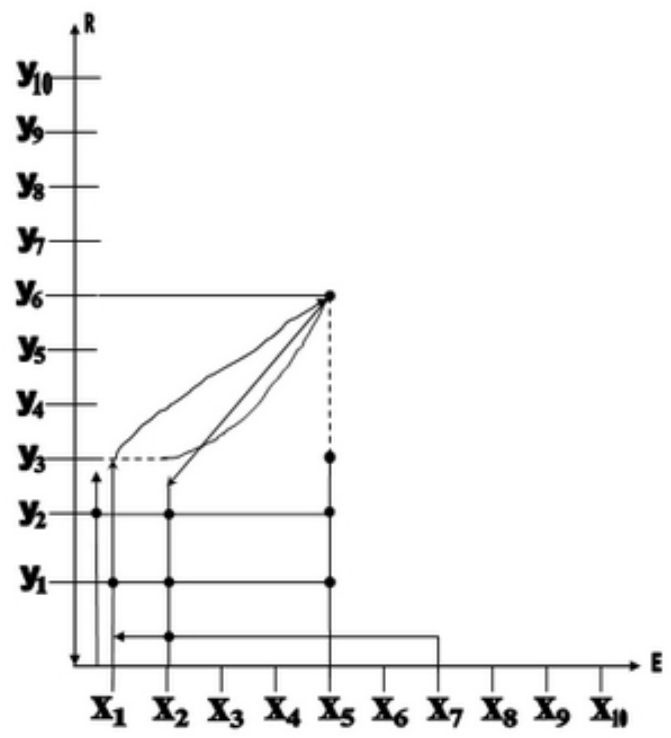




\section{How is a model of subject knowledge built for machine learning?}

In order to build a model of subject knowledge for machine learning without a teacher, the following needs to be done:

1. Divide structures of knowledge into variables that is into linguistic variables and invariant variables namely, into a universal set.

2. Invariant knowledge or universal set of knowledge is denoted by X.

3. This knowledge is classified divided into classes or elements of the set and is build on the horizontal. The resulting classes of invariant knowledge or elements of the set are denoted by $\times 0.1 \ldots \times 0,9$. Invariant knowledge or the set of knowledge can be finite or infinite according to the classification of the classes themselves.

4. Variable, categorical knowledge or linguistic variable are located vertically and denoted by U. They are also classified and denoted by $0.1 ; 0.2$ and etc [3]. In work [Nordhausen and Langley, 1990] it was noted that formation of categories - is the basis of a unified theory of scientific research. Denoting classes and groups of the set, as well as categorical knowledge of a linguistic variable in number, we can present this knowledge with their properties. Each property takes a serial number. So the sentence "The day was sunny" can be defined on a coordinate plane as points: xa, 1,1 y a, 1, x a, 5, $y$, a 4 / 1 xa, 2 ya1 / 5. Each element of the set, for example, $x 0,1$ is characterized by its own linguistic variable - y0,. Numerical parameters $\mathrm{x} 0,1,1$ by the rules of Russian grammar mean masculine noun, y0, 1 mean a single number, etc. Analogous to these characters, a set of proposals on the basis of available knowledge can be constructed. This property can be one of the justifications for machine learning without a teacher as it was derived from an example of the natural language. Each class of knowledge or element of the set is at the same time, a cluster of the structure of knowledge. They have their own rules and laws. Structures of knowledge clusters can be combined, divided, associated and canceled according to logical settings of rules of a linguistic variable. Belonging of the linguistic variable into elements of the set or the logical structures of clusters is determined by logical operations such as operation of substitution, enrichment, identical and multiplicative operations. That is, in this case as the rules of linguistic variable and the rules of elements of the set are in mobile motion all the time, by combining according to the given settings around the logical structure of knowledge or elements of the set become nanostructures of knowledge.

\section{What innovations can bring this knowledge model in education?}

1. Knowledge is considered in the scheme of integrity. Since language is a means of communication and expression of ideas, then, certainly, the conditions of integrity scheme and logic of Zadeh can be in any scientific knowledge and the rules of logic of Piaget and fuzzy logic can be applied to them.

2. Structures of knowledge will be divided into invariant and variable or into syntactic and semantic. Numeric designation of categorical and invariant properties of knowledge makes it possible to build coordinates of knowledge on the basis of which the process of knowledge construction will go.

3. Operationality of thinking enables to collect structures of knowledge into clusters, figure out their interrelationship and attitudes, classify them, enrich, or replace with the other structures. These logical operations gather as a magnet around the structures of 
knowledge relating to them relevant knowledge and turn them into a nanostructure of knowledge.

4. The logic of integrity by Piaget and fuzzy logic by Zadeh break down the traditional vertical construction of structures of knowledge and arrange them into a horizontal structure (Ф.Бунятова 1990) Such construction of knowledge based on psychology, pedagogy, and high technology, in its turn makes nanopsychopedagogical approach to training (F.Bunyatova 2009)].

\section{References}

Gordon Dryden\&DR.Jannette Voz (2000) The learning revolution. The learning web.

F.Bunyatova IETC(2009) Ankara, Turkey Constructive teaching technology and perspectives of nanopsychopedagogy. Ankara, Turkey

Ф. Д. Бунятова. (01.07.02). Baku Применение нечётной логики в образовательных технологиях CopyrightAgency of the Azerbaijan Republic № 328

Ф.Д.Бунятова (2007) Педагогическая технология. Конструктивное обучение. URLwww. Eidos-internet-magazine.

Ф.Д. Бунятова. AICT-2009 Baku . Логика целостности, нечетка логика и моделирование содержания предметных знаний.

Ф. Д. Бунятова. (1990) Баку Логический способ обучения. Альтернативное образование.Баку 1990 Маариф

Жан Пиаже. ( 2001) Москва. Избранные труды.

В. Я. Пивкин, Е. П. Бакулин, Д. И. Коренькова Нечеткие множества в системах управления. URL www. allmath.ru/appliedmath

Лотфи Аскер Заде. (1976). Москва. Мир.Понятие лингвистической переменной и его применение к принятию приближенных решений

F. C. Bunyatova, (2008) Bakı Konstruktiv təlim. Mahiyyəti, prinsip, vəzifələr və dərslərdən numunələr

Р. А. Алиев, (1999) Баку Soft computering. Баку. АзДНА.

Ф. Д. Бунятова. (2001) Жан Пиаже в школе. Elmi axtarışlar. Bakı.

Nordhausen and Langley, 1990 URL.www.filosof.historic.ru/books 


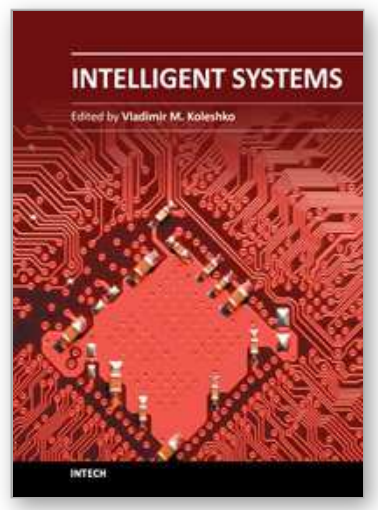

\author{
Intelligent Systems \\ Edited by Prof. Vladimir M. Koleshko
}

ISBN 978-953-51-0054-6

Hard cover, 366 pages

Publisher InTech

Published online 02, March, 2012

Published in print edition March, 2012

This book is dedicated to intelligent systems of broad-spectrum application, such as personal and social biosafety or use of intelligent sensory micro-nanosystems such as "e-nose", "e-tongue" and "e-eye". In addition to that, effective acquiring information, knowledge management and improved knowledge transfer in any media, as well as modeling its information content using meta-and hyper heuristics and semantic reasoning all benefit from the systems covered in this book. Intelligent systems can also be applied in education and generating the intelligent distributed eLearning architecture, as well as in a large number of technical fields, such as industrial design, manufacturing and utilization, e.g., in precision agriculture, cartography, electric power distribution systems, intelligent building management systems, drilling operations etc. Furthermore, decision making using fuzzy logic models, computational recognition of comprehension uncertainty and the joint synthesis of goals and means of intelligent behavior biosystems, as well as diagnostic and human support in the healthcare environment have also been made easier.

\title{
How to reference
}

In order to correctly reference this scholarly work, feel free to copy and paste the following:

Fatma Khanum Bunyatova (2012). Logic of Integrity, Fuzzy Logic and Knowledge Modeling for Machine Education, Intelligent Systems, Prof. Vladimir M. Koleshko (Ed.), ISBN: 978-953-51-0054-6, InTech, Available from: http://www.intechopen.com/books/intelligent-systems/logic-of-integrity-fuzzy-logic-and-knowledgemodeling-for-machine-education

\section{INTECH}

open science | open minds

\section{InTech Europe}

University Campus STeP Ri

Slavka Krautzeka 83/A

51000 Rijeka, Croatia

Phone: +385 (51) 770447

Fax: +385 (51) 686166

www.intechopen.com

\section{InTech China}

Unit 405, Office Block, Hotel Equatorial Shanghai

No.65, Yan An Road (West), Shanghai, 200040, China

中国上海市延安西路 65 号上海国际贵都大饭店办公楼 405 单元

Phone: +86-21-62489820

Fax: $+86-21-62489821$ 
(C) 2012 The Author(s). Licensee IntechOpen. This is an open access article distributed under the terms of the Creative Commons Attribution 3.0 License, which permits unrestricted use, distribution, and reproduction in any medium, provided the original work is properly cited. 